\title{
Comportamento ingestivo de caprinos das raças Moxotó e Canindé em confinamento recebendo dois níveis de energia na dieta ${ }^{1}$
}

\author{
Lígia Maria Gomes Barreto ${ }^{2}$, Ariosvaldo Nunes de Medeiros ${ }^{3}$, Ângela Maria Vieira Batista ${ }^{4}$, \\ Dermeval Araújo Furtado ${ }^{5}$, Gherman Garcia Leal de Araújo ${ }^{6}$, Ana Cristina Chacon Lisboa ${ }^{2}$, \\ Jória Leilane de Albuquerque Paulo², Cicília Maria Silva de Souza ${ }^{7}$
}

\author{
1 Projeto financiado CNPq/CAPES. \\ 2 Programa de Pós-graduação em Zootecnia/CCA/UFPB - Areia-PB. \\ ${ }^{3}$ Departamento de Zootecnia/CCA/UFPB - Areia-PB. \\ ${ }^{4}$ Departamento de Zootecnia/UFRPE - Recife-PE. \\ 5 Unidade Acadêmica de Engenharia Agrícola/UFCG - Campina Grande-PB. \\ ${ }^{6}$ CPATSA/Embrapa Semiárido-Petrolina-PE. \\ 7 Programa de Doutorado Integrado em Zootecnia/CCA/UFPB.
}

RESUMO - Neste trabalho foi avaliado o comportamento ingestivo de caprinos nativos do semiárido nordestino mantidos em confinamento. Foram utilizados 40 machos castrados, 20 da raça Moxotó e 20 Canindé, com peso médio inicial de $15,22 \mathrm{~kg} \pm 1,78 \mathrm{~kg}$, distribuídos aleatoriamente em delineamento inteiramente casualizado, em arranjo fatorial $2 \times 2$, com duas raças e duas dietas. Foram avaliadas duas dietas experimentais: uma com menor nível energético (2,2 Mcal de EM/kg de MS), formulada com relação volumoso:concentrado 70:30; e outra com maior nível energético (2,7 Mcal de EM/kg de MS) e relação volumoso:concentrado de 35:65. Para o comportamento ingestivo, foram realizadas observações a cada cinco minutos, durante 24 horas, para determinação do tempo despendido em alimentação, ruminação e ócio. O consumo de matéria seca, o número de bolos ruminados e de mastigações merícicas por dia, o tempo de mastigação merícica por bolo, a frequência urinária e de procura por água e o consumo de água variaram significativamente entre as raças. Os animais da raça Moxotó apresentaram maior frequência urinária e menor procura por água ao longo do dia. Entretanto, recebendo a dieta com 2,7 Mcal de EM/kg de MS, excretaram menor quantidade de urina. Caprinos das raças Moxotó e Canindé são muito seletivos e têm maior preferência pelas partículas pequenas da dieta, independentemente do seu nível energético. O fornecimento de dietas com alto nível de energia favorece a eficiência alimentar e de ruminação de caprinos Moxotó e Canindé em confinamento.

Palavras-chave: alimentação, descanso, raça nativa, ruminação

\section{Ingestive behaviour of Moxoto and Caninde goats fed diets with two energy levels in feedlot}

\begin{abstract}
In this work, it was evaluated the ingestive behavior of indigenous goats from the northeastern semiarid region, kept in feedlot. Forty castrated males, 20 from Moxotó and 20 from Caninde breeds, with average initial weight of $15.22 \mathrm{~kg} \pm 1.78 \mathrm{~kg}$, were used. The goats were distributed in a completely randomized design in a $2 \times 2$ factorial arrangement with two breeds and two diets. Two experimental diets were evaluated: diet with lower energy level (2.2 Mcal ME/kg dry matter (DM)) formulated with 70:30 roughage:concentrate ratio;and another diet with higher energy level, (2.7 Mcal ME/kg DM) and roughage:concentrate ratio of 35:65. For ingestive behavior, observations were carried out at every five minutes for 24 hours to determine time spent on intake, rumination and idle. Dry matter intake, number of ruminated boli and ruminating chews per day, time of ruminating chews per boli, urinary frequency and frequency of search for water and water intake significantly differed among breeds. Moxoto breed animals showed higher urinary frequency and lower frequency for search for water during the day. However, when Moxoto animals received the diet with 2.7 Mcal ME/kg DM, they excreted less urine. Moxoto and Caninde goats are very selective with greater preference for small particles of the diets, regardless to its energy level. Supply of diets with high level of energy improves feed and rumination efficiency of Moxoto and Caninde goats in feedlot.
\end{abstract}

Key Words: feeding, idleness, native breed, rumination 


\section{Introdução}

A caprinocultura tem se desenvolvido rapidamente nos últimos anos, todavia as pesquisas têm sido direcionadas quase que estritamente às áreas de nutrição, melhoramento genético e reprodução. Apesar de as abordagens contribuírem muito, trazendo inúmeros benefícios para os setores de produção de carne e leite, é necessário entender o comportamento ingestivo dos caprinos para ajuste do manejo e obtenção de melhor desempenho (Carvalho et al., 2007).

O estudo do comportamento ingestivo é relevante para a nutrição animal, pois permite entender os fatores que atuam na regulação da ingestão de alimentos e água e estabelecer ajustes que melhorem a produção (Mendonça et al., 2004).

Os pequenos ruminantes têm a capacidade de adaptação às mais diversas condições de alimentação, manejo e ambiente, modificando seus parâmetros de comportamento ingestivo para alcançar e manter determinado nível de consumo compatível com as exigências nutricionais, o qual depende de outras variáveis, como a qualidade dos ingredientes da ração, sobretudo as forragens, e os teores de fibra, que está associada ao estímulo da mastigação, produção de saliva, motilidade do rúmen e manutenção ruminal (Silanikove, 1992; Cardoso et al., 2006).

Além disso, se a densidade energética da ração for alta, isto é, com baixa concentração de fibra em relação às exigências do animal, o consumo será limitado pela demanda energética e o animal poderá deixar de ingerir alimentos, mesmo que o rúmen não esteja repleto. Por outro lado, se a dieta for de baixa densidade energética, o consumo será limitado pela repleção ruminal (Ítavo et al., 2002). Dessa forma, estudos de comportamento têm sido largamente utilizados no desenvolvimento de modelos para suporte às pesquisas e às formas de manejo dos animais de interesse zootécnico, sobretudo para as raças nativas do Nordeste, como é o caso das raças Moxotó e Canindé.

Portanto, este trabalho foi conduzido com o intuito de avaliar parâmetros do comportamento ingestivo e a seletividade de caprinos nativos em confinamento na região semiárida paraibana alimentados com dietas de dois níveis de energia metabolizável.

\section{Material e Métodos}

O experimento foi conduzido durante os meses de agosto a novembro de 2007 utilizando-se 40 caprinos com média de 4 meses de idade, 20 da raça Moxotó e 20 da raça Canindé, com peso vivo médio inicial de 15,29 \pm 1,76 kg e
$15,31 \pm 1,94 \mathrm{~kg}$, respectivamente. Esses animais foram everminados, distribuídos aleatoriamente de acordo com a raça e o nível de energia da dieta e alojados em galpão aberto, disposto no sentido leste-oeste, coberto com telhas de cerâmica e piso em chão batido, com baias individuais de 3,75 $\mathrm{m}^{2}$ cada uma, providas de comedouro e bebedouro.

A ração fornecida aos animais (Tabela 1) foi composta de feno de maniçoba (Manihot sp) e concentrado à base de farelo de milho, farelo de soja, melaço de cana-deaçúcar e suplemento mineral. A maniçoba utilizada para a confecção do feno foi colhida em áreas de ocorrência natural da Caatinga quando as plantas se encontravam em estágio vegetativo de floração e frutificação.

A dieta foi formulada com base no NRC (1981) de forma a proporcionar ganho de peso diário de 120 g e 165 g com as dietas de menor e maior nível energético, respectivamente, para animais de $15 \mathrm{~kg}$ de peso vivo.

O arraçoamento dos animais foi realizado duas vezes ao dia, às 7 e 15 h, com ajuste diário do consumo, de modo a permitir 20\% de sobras. A água foi fornecida à vontade e o consumo quantificado diariamente durante o período de observação, descontando-se as perdas evaporativas pela diferença após 24 horas, sendo a quantidade de água pesada em balança de precisão, no mesmo horário de fornecimento aos animais, utilizando-se oito baldes em diferentes pontos do galpão.

Tabela 1 - Composição da dieta experimental (MS\%)

\begin{tabular}{lcc}
\hline Ingrediente & \multicolumn{2}{c}{$\begin{array}{c}\text { Energia } \\
\text { metabolizável } \\
\text { (Mcal/kg de MS) }\end{array}$} \\
\hline Farelo de milho (subproduto industrial) & 2,2 & 2,7 \\
Farelo de soja & 6 & 57 \\
Melaço de cana em pó & 1 & 5 \\
Suplemento mineral ${ }^{1}$ & 1 & 1 \\
Calcário & 1 & 1 \\
Feno de maniçoba & 70 & 1 \\
Composição química calculada & & 35 \\
Matéria seca & 87,13 & 86,74 \\
Proteína bruta & 11,72 & 11,56 \\
Extrato etéreo & 4,90 & 7,79 \\
Fibra em detergente neutro corrigida & 53,69 & 45,02 \\
para cinzas e proteína & & \\
Fibra em detergente ácido & 41,54 & 26,17 \\
Carboidratos totais & 74,75 & 73,01 \\
Carboidratos não-fibrosos & 21,07 & 28,00 \\
Energia metabolizável estimada & 2,20 & 2,71 \\
(Mcal/kg de MS) & & \\
\hline 1 & &
\end{tabular}

${ }^{1}$ Suplemento mineral (nutriente/kg de suplemento): vitamina A - 135.000,00 U.I.; vitamina D3 - 68.000,00 U.I.; vitamina E - 450,00 U.I.; cálcio - 240 g; fósforo - 71 g; potássio - 28,2 g; enxofre - 20 g; magnésio - 20 g; cobre - $400 \mathrm{mg}$; cobalto - $30 \mathrm{mg}$; cromo - $10 \mathrm{mg}$; ferro - $2.500 \mathrm{mg}$; iodo - $40 \mathrm{mg}$; manganês - $1.350 \mathrm{mg}$; selênio - 15 mg; zinco - 1.700 mg; flúor máximo 710 mg; solubilidade do fósforo em ácido cítrico a $2 \%$ (minutos). 
As amostras das rações completas, dos ingredientes que compunham as rações experimentais e das sobras deixadas pelos animais foram colhidas durante três dias antecedentes às observações, acondicionadas em sacos plásticos e armazenadas em congelador a $-20^{\circ} \mathrm{C}$ para posteriores análises químicas.

As análises bromatológicas foram realizadas no Laboratório de Nutrição Animal do CCA/UFPB. Foram determinados os teores de matéria seca (MS), proteína bruta (PB) e extrato etéreo (EE) segundo a AOAC (2005). Para determinação da fibra em detergente neutro (FDN) e fibra em detergente ácido (FDA), utilizou-se a metodologia determinada pelo fabricante do aparelho ANKON, da Ankon Tecnology Corporation, com modificações relacionadas aos sacos, uma vez que foram utilizados sacos de TNT (tecido-não-tecido) gramatura $100 \mathrm{~mm}$, confeccionados no mesmo Laboratório. As amostras de FDN foram corrigidas para cinzas e proteína, os resíduos da fibra insolúvel em detergente neutro foram incinerados em mufla a $600^{\circ} \mathrm{C}$ por 4 horas para determinação de cinzas e a correção para proteína foi realizada através da proteína insolúvel em detergente neutro (PIDN).

Para a estimativa dos carboidratos totais (CT), utilizou-se a seguinte equação propostas por Sniffen et al. (1992), $\mathrm{CT}(\%)=100-(\% \mathrm{~PB}+\% \mathrm{EE}+\%$ Cinzas $)$. Os carboidratos não-fibrosos (CNF) foram calculados de acordo com Weiss (1999) como: CNF (\%) $=100-(\%$ FDNcp $+\%$ PB + $\%$ EE + \%cinzas).

A determinação granulométrica da dieta ofertada (Tabela 2) e das sobras deixadas pelos animais foi realizada no Laboratório de Física do Solo do CCA/UFPB. As amostras foram retiradas do congelador e colocadas em estufa a $55^{\circ} \mathrm{C}$ para retirada da umidade do material. Posteriormente, foram pesados em média $100 \mathrm{~g}$ do material, que foram postos em um conjunto de peneiras com diâmetros 2,00; 1,00 e 0,50 milímetros, sobrepostas de forma decrescente, e acopladas a um fundo fechado, onde se alojavam as partículas menores que $0,50 \mathrm{~mm}$. O material foi mantido em aparelho vibratório por 10 minutos e, após este tempo, o material retido em cada peneira foi colocado individualmente em bandejas identificadas e pesos conhecidos para quantificação da granulometria por meio do registro do peso.
As observações referentes ao comportamento ingestivo dos animais foram feitas em três períodos distintos com intervalos de sete dias, iniciando-se sempre às $6 \mathrm{~h}$ e perfazendo um período de 24 horas ininterruptas, de forma visual, pelo método de varredura instantânea proposto por Jonhson \& Combs (1991), a intervalos de 5 minutos, por observadores previamente treinados. As variáveis comportamentais observadas e registradas foram: ócio em pé, ócio deitado, em pé comendo, em pé ruminando e deitado ruminando. Analisaram-se, a partir desses dados, os tempos médios despendidos em alimentação, ruminação e ócio, observando-se também de forma contínua o número de vezes em que o animal defecou, urinou e procurou água. A procura por água foi registrada como sendo o número de vezes que o animal procurava o bebedouro e ingeria água.

Para avaliação da mastigação merícica, foram utilizados cinco animais de cada tratamento, em dois períodos, das 22 a 00 hora e das 4 às $6 \mathrm{~h}$. Esse período foi determinado para observação da mastigação merícica, uma vez que a maior frequência de ruminação ocorre nesses horários, a partir de observações preliminares, determinando-se o número de mastigações merícicas e o tempo despendido na ruminação de cada bolo ruminal (segundos/bolo), com a utilização de cronômetro digital. Essa mastigação foi calculada através de três tempos de 15 segundos, sendo a média multiplicada por quatro para a obtenção do tempo de mastigação/minuto.

Os resultados referentes ao comportamento ingestivo foram obtidos pelas relações (Polli et al., 1996): EAL = $\mathrm{CMS} / \mathrm{TAL}$ (g MS/h); ERU = CMS/TRU (g MS/h); TMT = TAL+TRU (horas/dia); NBR = TRU/TMMB (n\%/dia); e $\mathrm{NMMD}=\mathrm{NBR} \times \operatorname{NMMB}\left(\mathrm{n}^{\circ} /\right.$ dia $)$, em que: $\mathrm{EAL}(\mathrm{g} M S /$ hora $)=$ eficiência de alimentação; CMS (g MS/dia) = consumo de matéria seca; TAL (horas/dia) = tempo de alimentação; ERU (g MS/hora) = eficiência de ruminação; TRU (horas/dia) = tempo de ruminação; TMT (hora/dia) = tempo de mastigação total; NBR $\left(n^{\%} /\right.$ dia $)=$ número de bolos ruminais; $\mathrm{TRU}(\mathrm{s} / \mathrm{dia})=$ tempo de ruminação; $\mathrm{TMMB}$ (s/bolo) = tempo de mastigações merícicas por bolo ruminal; segundo Bürger et al. (2000), $\operatorname{NMMD}\left(\mathrm{n}^{\circ} /\right.$ dia $)=$ número de mastigações merícicas; e $\operatorname{NMMB}\left(\mathrm{n}^{\circ} /\right.$ bolo $)=$ número de mastigações merícicas por bolo.

Tabela 2 - Porcentagem do tamanho da partícula nas dietas experimentais

\begin{tabular}{ccc}
\hline Tamanho da partícula $(\mathrm{mm})$ & Dieta com 2,2 Mcal de EM & Dieta com 2,7 Mcal de EM \\
\hline$\geq 2,00$ & 21,60 & 6,70 \\
$2,00-1,00$ & 24,36 & 31,69 \\
$1,00-0,50$ & 29,44 & 30,57 \\
$<0,50$ & 24,61 & 31,04 \\
\hline
\end{tabular}


Não apenas durante as observações noturnas, mas em todo o experimento, o ambiente foi mantido com iluminação artificial.

O delineamento experimental utilizado foi o inteiramente casualizado com arranjo fatorial $2 \times 2$ (duas raças e dois níveis de energia na dieta), com 10 repetições por tratamento, totalizando 40 parcelas. Os dados foram avaliados por meio de análise de variância e as médias comparadas pelo teste de F, a $5 \%$ de probabilidade.

\section{Resultados e Discussão}

Não houve efeito da raça nem da interação raça $\times$ dieta $(\mathrm{P}>0,05)$ sobre o tamanho de partículas contidas nas sobras das dietas ofertadas aos caprinos Moxotó e Canindé. Os animais de ambas as raças apresentaram comportamento semelhante quanto à seletividade da dieta ofertada, não diferindo estatisticamente. Entretanto, houve diferença $(\mathrm{P}<0,01)$ entre as dietas oferecidas quanto ao tamanho de partícula selecionado, exceto para o tamanho entre 2,0 e 1,0 mm (Tabela 3).

A dieta ofertada com maior nível energético (2,7 Mcal) apresentou $69 \%$ menos partículas menores que 2,0 mm, no entanto, houve tendência, para ambas as raças, em deixar maior quantidade de partículas desse tamanho nas sobras. Entretanto, os animais que consumiram a dieta de menor concentração energética deixaram maior quantidade de partículas maiores que 2,0 mm, em razão da maior relação volumoso:concentrado dessa dieta. Com exceção do tamanho de partícula entre 2,0 e 1,0 mm, houve diferença $(\mathrm{P}<0,05)$ entre as dietas para os demais tamanhos de partícula.

De maneira geral, em ambas as dietas, os animais apresentaram maior consumo de partículas de 1,0 a 0,50 mm, provavelmente em consequência da maior oferta desta granulometria na dieta. No entanto, as partículas $>2,0 \mathrm{~mm}$ foram deixadas em maior proporção para ambas as dietas, quando comparados ao que foi ofertado. Ribeiro et al. (2006a) também não encontraram diferença significativa na seletividade entre as raças Moxotó e Canindé. No entanto, esses resultados divergem dos encontrados nesta pesquisa com relação ao tamanho preferencial da partícula por esses animais. Esses autores revelam que as raças Moxotó e
Canindé deram maior preferência ao tamanho de partículas maiores 1,7 mm, com médias de 9,17\% e 17,60\% para as raças Canindé e Moxotó, respectivamente. Constataram ainda que a maior porcentagem de rejeição entre as raças foi das partículas cujo tamanho foi inferior a 0,6 $\mathrm{mm}$ e registraram médias de 29,64\% para ambas as raças.

Hadjigeorgiou et al. (2003) testaram a eficiência de ingestão e de digestão entre caprinos e ovinos fornecendo feno com três tamanhos de partícula: longo $(13,29 \mathrm{~mm})$, médio $(7,26 \mathrm{~mm})$ e curto $(0,69 \mathrm{~mm})$ e observaram que os ovinos aumentaram a ingestão de matéria seca quando o tamanho da partícula foi reduzido, embora a digestibilidade e o tempo de retenção tenha sido menor, enquanto, entre os caprinos, não houve diferença significativa no consumo de MS, na digestibilidade e no tempo retenção entre os tamanhos de partícula. Esses resultados levaram os autores a concluir que os caprinos apresentam maior eficiência mastigatória, tanto nos processos de ingestão como de nos ruminação, e desenvolvem mecanismos de resposta diferentes para cada comprimento de partícula, não alterando a ingestão, a digestibilidade ou o tempo de retenção ruminal.

De acordo com revisão feita por Allen (1996), grande parte da redução no tamanho de partículas grandes ocorre no retículo-rúmen e é ocasionada por uma combinação de resultados decorrentes da mastigação primária e da ruminação, com redução relativamente baixa promovida pela digestão (fermentação). A fermentação não tem efeito direto sobre a redução, porém aumenta fragilidade dos tecidos, facilitando a mastigação dos mesmos. Entretanto, pouca ou nenhuma redução ocorre depois que as partículas deixam o retículo-rúmen, pela ausência de enzimas capazes de degradar celulose no abomaso ou intestino delgado. Dados da literatura encontrados por esse autor indicam que o conceito de tamanho de partícula é usado para descrever o fluxo retículo-ruminal, mas que pode depender da forma física do alimento e da ingestão de matéria seca.

Não houve efeito significativo das raças nos tempos despendidos em alimentação, ruminação e ócio, que variaram $(\mathrm{P}<0,05)$ apenas entre as dietas ofertadas. A dieta com maior nível energético (Figura 1 a) proporcionou maior tempo em ócio, principalmente no período das 10 às 18 horas do dia, inversamente ao que ocorreu para a dieta de menor oferta

Tabela 3 - Tamanho de partículas contidas nas sobras da dieta ofertada a caprinos Moxotó e Canindé

\begin{tabular}{|c|c|c|c|c|c|}
\hline \multirow[t]{2}{*}{ Tamanho de partícula (mm) } & \multicolumn{2}{|c|}{ Moxotó } & \multicolumn{2}{|c|}{ Canindé } & \multirow[t]{2}{*}{ CV $(\%)$} \\
\hline & 2,2 Mcal & 2,7 Mcal & 2,2 Mcal & 2,7 Mcal & \\
\hline$\geq 2,00$ & 23,15 & 8,68 & 27,49 & 9,85 & 68,99 \\
\hline $2,00-1,00$ & 28,67 & 29,2 & 27,75 & 29,09 & 23,38 \\
\hline $1,00-0,50$ & 22,81 & 25,37 & 22,30 & 25,96 & 15,62 \\
\hline$<0,50$ & 25,37 & 36,94 & 22,46 & 35,10 & 24,89 \\
\hline
\end{tabular}


energética, pela quantidade de volumoso presente nesta dieta, houve maior atividade mastigatória. Para os animais submetidos a dieta de menor aporte energético (Figura 1 b), o maior tempo em ócio compreende o período das 16 às 19 $\mathrm{h}$ do dia, corroborando os resultados encontrados por Ribeiro et al. (2006b). Das três atividades observadas, o tempo de ócio foi a que se manteve mais constante ao longo do dia, em ambas as dietas.

Durante a noite, a atividade ruminação foi mais freqüente; começou por volta das $22 \mathrm{~h}$, continuando de forma crescente até às $7 \mathrm{~h}$, quando teve seu maior pico, para ambas as dietas ofertadas. Esse resultado difere dos relatos de Fischer et al. (1998), Tavares et al. (2005) e Ribeiro et al. (2006b), que encontraram dois picos diferentes, o primeiro das 22 à 00 hora e o segundo das 4 às 6 h. É evidente que a ruminação diminui ao longo do dia, período em que é fornecida a alimentação dos animais.

Não houve efeito das raças $(P>0,05)$ nas variáveis analisadas, exceto para o consumo de fibra em detergente neutro em kg por dia (Tabela 4). Contudo, houve efeito do nível energético da dieta $(\mathrm{P}<0,05)$ nos tempos de ruminação e ócio, no consumo de fibra em detergente neutro em percentagem do peso vivo, na eficiência de alimentação e no tempo de mastigação total.

Esses resultados indicam semelhança entre as raças, as quais, de acordo com Ribeiro et al. (2006b), atingem na idade adulta tamanho corporal muito próximo e possuem velocidade de crescimento semelhante, provavelmente por terem sido submetidos às mesmas condições ambientais no processo de adaptação quando trazidas ao semiárido nordestino. Outro fato que pode ter contribuído para essa semelhança é que as raças foram submetidas às mesmas condições de manejo. Além disso, os animais estavam dentro da zona de conforto térmico para caprinos adultos, entre 20 e $30^{\circ} \mathrm{C}$ de acordo com Baêta \& Souza (1997).

A dieta com menor nível energético proporcionou maior tempo de ruminação (8,37 horas/dia) e menor tempo em ócio (9,93 horas/dia), correspondentes a 34,88 e a 41,38\% do dia, respectivamente, se comparados ao tempo despendido para essas atividades na dieta com maior nível energético,
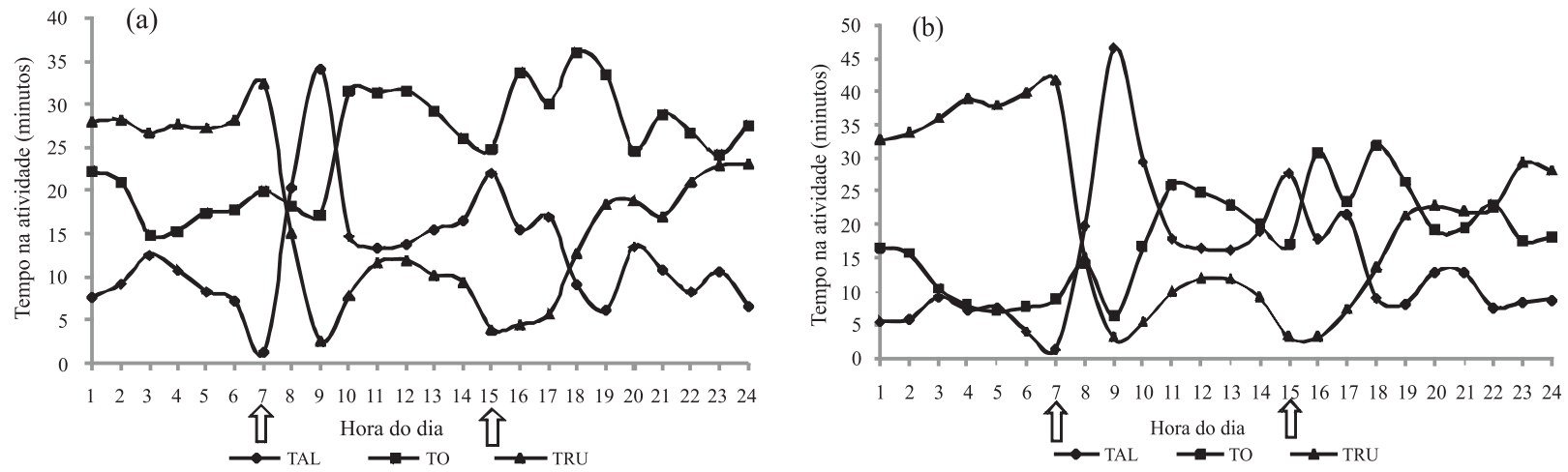

Figura 1 - Alimentação, ócio e ruminação de caprinos, durante 24 horas, consumindo dieta de 2,7 Mcal (a) e 2,2 Mcal (b) de EM/kg de MS.

Tabela 4 - Tempos em alimentação, ruminação e ócio, consumos de MS e FDN e eficiências de alimentação e ruminação em caprinos das raças Moxotó e Canindé recebendo dietas de dois níveis energéticos

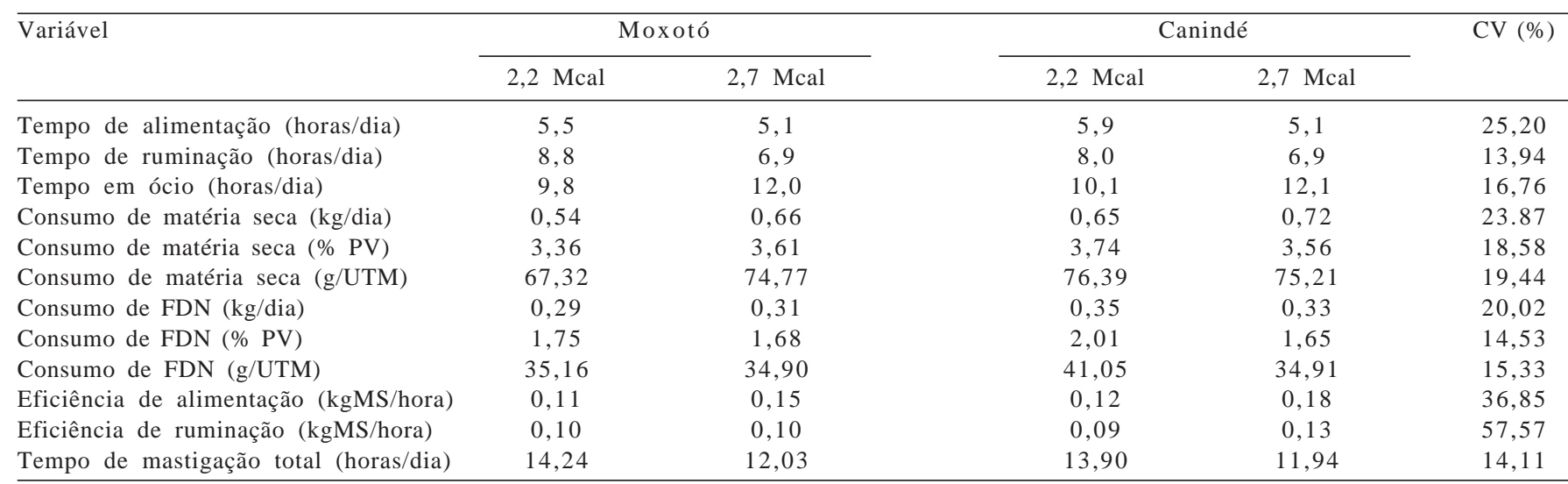


que foram de 6,90 horas/dia e 12,01 horas/dia (28,75\% e $50,04 \%$ do dia), para ruminação e ócio, respectivamente. Pode-se inferir que a quantidade de $70 \%$ de feno de maniçoba utilizada na dieta com menor nível de energia foi um dos fatores que influenciou esses resultados, devido ao maior nível de fibra em detergente neutro na ração e ao maior consumo desse componente nutricional, em percentagem do peso vivo (Tabela 4), acarretando maior tempo de retenção da digesta no rúmen.

Van Soest (1994) relatou que, para animais estabulados, o tempo gasto com alimentação é de aproximadamente uma hora para alimentos com alta proporção de grãos e até mais de seis horas para fontes com alto teor de volumoso. Assim, o tempo despendido em ruminação é influenciado pela natureza da dieta e provavelmente é proporcional à quantidade de parede celular dos volumosos, ou seja, quanto maior o teor de fibra na dieta, maior o tempo despendido em ruminação. No entanto, nesta pesquisa não foi verificada diferença no tempo de alimentação entre as dietas oferecidas.

De acordo com Fischer et al. (1998), existem diferenças entre indivíduos quanto à duração e à distribuição das atividades de ingestão e ruminação, que parecem estar relacionadas ao apetite dos animais, às diferenças anatômicas e ao suprimento das exigências energéticas ou repleção ruminal, que seriam influenciadas pela relação volumoso:concentrado. Neste trabalho, foram constatadas diferenças relacionadas apenas no tempo gasto com ruminação entre as dietas consumidas.

O aumento do nível de carboidratos não-fibrosos e a diminuição da fibra em detergente neutro da dieta podem reduzir os períodos de alimentação e ruminação e, por consequência, elevar o tempo total diário do animal em ócio (Silva et al., 2005). Segundo Pereyra \& Leiras (1991), a ruminação depende da qualidade do alimento: quanto melhor a qualidade, menor o tempo de ruminação e vice-versa. De acordo com esses autores, o animal investe 5 a 9 horas do dia em ruminação.

Ribeiro et al. (2006b), em pesquisa com caprinos Moxotó e Canindé em confinamento submetidos a alimentação restrita e à vontade, não encontraram diferença significativa entre raças, dietas ou da interação entre elas para nenhuma das variáveis analisadas. No entanto, mesmo não havendo efeito significativo, os resultados encontrados nesta pesquisa são muito semelhantes aos descritos por esses autores para tempo de ruminação (8,03 e 7,92 horas/dia) e ócio (12,00 e 13,43 horas/dia) para animais que recebiam alimentação à vontade e restrita.

Não foi constatada diferença significativa nos consumos de matéria seca e proteína bruta, expressos em kg/dia, \% do PV e g/UTM, entre as raças, dietas ou interação entre elas (Tabela 4). De acordo com Mertens (1994), o consumo não é expresso da mesma forma para os mecanismos físicos e fisiológicos de controle, em rações de baixa qualidade, uma vez que a ingestão élimitada pelo enchimento do rúmen, assim, esse autor sugeriu expressá-lo em porcentagem do peso vivo, pois está mais relacionado ao tamanho e à capacidade do trato digestivo. Por outro lado, quando é limitado pela demanda fisiológica de energia, a melhor forma de expressá-lo é com base no peso metabólico. Entretanto, no caso deste estudo, isso não se aplica, pelo fato de não haver diferença nas variáveis analisadas.

As eficiências de alimentação (EALms) e de ruminação de matéria seca (ERUms) e o tempo de mastigação total (TMT) não foram influenciados $(\mathrm{P}>0,05)$ pela raça, comprovando mais uma vez que os animais apresentam comportamento semelhante (Tabela 4). Os animais que consumiram a dieta com maior oferta de energia demonstraram maior eficiência de alimentação, ou seja, consumiram maior quantidade de matéria seca por unidade de tempo, que foi 160 g versus 120 g de matéria seca por hora para os animais em que era ofertada menor quantidade de energia na dieta, 0 que representa um tempo gasto de 22,5 e 30 segundos por grama de alimento consumido, respectivamente.

Durante o experimento, observou-se que, no momento em que era disponibilizada a ração, os animais que receberam a dieta de maior oferta energética consumiam com maior avidez se comparados àqueles que receberam a dieta de menor quantidade de energia. Esse fato pode estar relacionado à maior quantidade de volumoso na dieta com 2,2 Mcal de EM/kg de matéria seca, o que levou o animal a despender mais tempo selecionando os ingredientes da ração. Isso justifica a seleção de partículas menores que $2 \mathrm{~mm}$ feita pelos animais, uma vez que a dieta de menor concentração energética continha maior quantidade de partículas desse tamanho, diferentemente da dieta de maior nível energético (Tabelas 2 e 3).

Os animais que receberam a dieta de menor nível energético tiveram tempo de mastigação total superior àqueles que consumiram a dieta de maior nível energético. Isso pode ter ocorrido em razão da maior relação volumoso:concentrado (70:30) da dieta de menor nível energético, consequentemente, pelo maior teor de fibra em detergente neutro (53,09\%) que levou os animais a passar mais tempo ruminando, proporcionando aumento no tempo de mastigação total (Tabela 4).

Houve efeito da raça $(\mathrm{P}<0,01)$ e da interação raça vs dieta $(\mathrm{P}<0,01)$ para o número de bolos ruminais e, com o desdobramento da interação, verificou-se que, para raças dentro de dietas, houve efeito $(\mathrm{P}<0,05)$ apenas para a raça 
Canindé. Entretanto, para o efeito das dietas dentro das raças, apenas a dieta de menor nível energético teve efeito $(\mathrm{P}<0,01)$ (Tabela 5).

Para o número diário de mastigações merícicas, os resultados comprovaram a mesma tendência do número de bolos ruminais, uma vez que não houve efeito significativo da dieta entre os animais da raça Moxotó, ao passo que a Canindé mastigou mais vezes por dia. Essa ocorrência é aceitável, uma vez que o número de mastigações merícicas por dia é diretamente proporcional ao número de bolos ruminais, ou seja, quanto maior o número de bolos ruminais por dia, maior será o número de mastigações diárias. Por outro lado, o tempo de mastigação merícica por bolo apresentou relação inversamente proporcional às demais variáveis. Por essa razão, a Canindé despendeu menos tempo mastigando cada bolo ruminal. Isto demonstra que a raça Moxotó é mais lenta nestas atividades, gastando maior tempo na mastigação por bolo ruminal, levando a menor número de bolos ruminais e de mastigações merícicas por dia.

Segundo Mertens (2001), o tempo de mastigação está relacionado ao consumo de matéria seca, à concentração de fibra em detergente neutro (FDN) da dieta e ao tamanho da partícula. Nesse sentido, embora o consumo de matéria seca tenha sido mais elevado para a dieta com 2,7 Mcal de energia metabolizável (EM), que, por sua vez, continha menor concentração de FDN (45,02\%), a dieta de 2,2 Mcal de EM proporcionou maior tempo de mastigação, associado também a maior relação volumoso:concentrado (70:30), com maior percentual de FDN (53,69\%). Outro fator que pode ter influenciado esse resultado foi a maior quantidade de concentrado na dieta de 2,7 Mcal, uma vez que, de acordo com Paulino et al. (2005), alimentos energéticos possuem maior coeficiente de digestibilidade, dessa forma, o tempo de mastigação necessário para essa dieta foi menor.

Nas variáveis fisiológicas, urina, fezes e procura por água, não houve efeito $(\mathrm{P}>0,05)$ da raça nem da dieta na frequência de defecação, cujas médias variaram de 6,17 a 6,87/dia para os animais que recebiam a dieta de menor nível de energia (Tabela 6).

Entre as raças, houve diferença $(P<0,05)$ nas variáveis fisiológicas e na frequência urinária e de procura por água, mas essa diferença não foi provocada pela dieta $(\mathrm{P}>0,05)$. No entanto, a dieta influenciou a quantidade de urina excretada $(\mathrm{P}<0,01)$, que foi maior nos animais que receberam o menor nível energético - as médias foram de 495,6 e 372,6 mL/dia para as raças Moxotó e Canindé, respectivamente - enquanto, entre aqueles que receberam a dieta de maior nível de energia, as médias foram de 215,8 mL/dia e 279,7 mL/dia para as raças Moxotó e Canindé. Mesmo ocorrendo diferença na frequência de procura por água, não houve efeito $(\mathrm{P}>0,05)$ no consumo de água, tanto em L/dia como em L/kg de MS consumida. Os animais da raça Moxotó urinaram mais que os da raça Canindé, em número de vezes ao dia e em L/dia, enquanto a procura por água foi maior entre os da raça Canindé.

De acordo com Pereyra \& Leiras (1991), os fatores que afetam o consumo de água são: calor, que promove aumento mais efetivo no consumo de água; consumo de matéria seca, que mantém uma relação direta com o consumo de água; suplementação mineral, que aumenta o consumo,

Tabela 5 - Médias das atividades de número de bolos ruminais e mastigação merícica em função da raça e da dieta ofertada

\begin{tabular}{|c|c|c|c|c|c|}
\hline \multirow[t]{2}{*}{ Atividade } & \multicolumn{2}{|c|}{ Moxotó } & \multicolumn{2}{|c|}{ Canindé } & \multirow[t]{2}{*}{ CV (\%) } \\
\hline & 2,2 Mcal & 2,7 Mcal & 2,2 Mcal & 2,7 Mcal & \\
\hline Bolos ruminais ( $\left.\mathrm{n}^{\circ} / \mathrm{dia}\right)$ & $140,12 \mathrm{Bb}$ & $153,54 \mathrm{Bb}$ & $176,73 \mathrm{Aa}$ & $152,03 \mathrm{Bb}$ & 14,26 \\
\hline Mastigação merícica por bolo $\left(n^{\circ}\right)$ & 108,91 & 94,12 & 96,84 & 98,22 & 27,52 \\
\hline Mastigação merícica por bolo (segundos) & 90,01 & 64,82 & 65,00 & 65,25 & 28,77 \\
\hline
\end{tabular}

Médias seguidas de letras iguais maiúsculas para raça e minúsculas para nível energético não diferem pelo teste $\mathrm{F}$ a 5\% de probabilidade.

Tabela 6 - Médias das variáveis fisiológicas, fezes, urina e procura por água em função da raça e da dieta ofertada

\begin{tabular}{|c|c|c|c|c|c|}
\hline \multirow[t]{2}{*}{ Variável } & \multicolumn{2}{|c|}{ Moxotó } & \multicolumn{2}{|c|}{ Canindé } & \multirow[t]{2}{*}{ CV $(\%)$} \\
\hline & 2,2 Mcal & 2,7 Mcal & 2,2 Mcal & 2,7 Mcal & \\
\hline Fezes (n\%/dia) & 6,87 & 6,30 & 6,70 & 6,17 & 31,99 \\
\hline Fezes (g/dia) & 489,0 & $214,0 \mathrm{~b}$ & 405,0 & $269,0 \mathrm{~b}$ & 31,74 \\
\hline Urina (n\%/dia) & 6,00 & 6,00 & 4,70 & 4,57 & 38,95 \\
\hline Urina (mL/dia) & 495,6 Аа & $215,8 \mathrm{Bb}$ & $372,6 \mathrm{Bb}$ & $279,7 \mathrm{Bb}$ & 36,12 \\
\hline Água (n\%/dia) & 2,80 & 2,90 & 4,97 & 4,43 & 71,63 \\
\hline Consumo de água (L/dia) & 1,57 & 1,55 & 1,48 & 1,55 & 30,40 \\
\hline Consumo de água (L/kg MS) & 2,99 & 2,39 & 2,22 & 2,28 & 29,47 \\
\hline
\end{tabular}

Médias seguidas de letras iguais maiúsculas para raça e minúsculas para nível energético não diferem pelo teste $\mathrm{F}$ a 5\% de probabilidade. 
principalmente em fêmeas gestantes e lactantes; e confinamento, animais estabulados tendem ao aumentar o consumo em relação aos que estão em pastejo.

Outro fato que pode ter influenciado na maior procura por água pelos animais da raça Canindé é a coloração escura da pelagem desses caprinos, que promove maior absorção de calor do ambiente, levando-os a procura mais frequente por água. Com isso, a dissipação do calor ocorrerá pela conversão da água em forma de vapor, tanto pelo suor secretado pelas glândulas da pele quanto pela umidade do trato respiratório (Baêta \& Souza, 1997), o que justifica a menor frequência urinária. Por outro lado, segundo revisão feita por Morand-Fehr \& Dureau (2001), a redução no consumo de água não reduz sua excreção pela urina.

Lisboa et al. (2010), em pesquisa com as carcaças de animais dessa raça, encontrou diferença $(\mathrm{P}<0,05)$ no peso do pulmão, que foi maior nos animais da raça Canindé. Isso reforça a afirmativa de que podem ter adquirido ao longo do tempo maior eficiência respiratória, facilitando as trocas de calor pela respiração. Segundo Ferreira et al. (2002), caprinos necessitam de menos água que os ovinos para ganhar um quilo de peso vivo e dietas com mais energia ocasionam maior consumo de água que as de baixa energia.

De acordo com relatos encontrados por Silva (2006), a ingestão de água está relacionada ao metabolismo energético e ao consumo de oxigênio. Para que ocorra a utilização do alimento pelo corpo, a água é inicialmente necessária para mastigar e engolir o alimento, assim como para os processos de digestão, que requerem homogeneização e translocação da digesta e dos fluidos dentro do lúmen gastrintestinal. Contudo, a estreita relação entre ingestão de água e de alimento reflete as múltiplas interações de água e trocas energéticas em nível de tecidos e células.

Torreão (2007) enfatiza que essa informação dá suporte à ideia de que o aumento da concentração energética da dieta pode ser um eficiente caminho para amenizar o estresse pelo calor, uma vez que nessa situação aumentaria o consumo de água. Entretanto, neste estudo, o nível energético da dieta não influenciou a ingestão de água.

\section{Conclusões}

Caprinos das raças Moxotó e Canindé são muito seletivos e preferem as menores partículas da dieta, independentemente do seu nível energético. Dietas com alto nível de energia favorecem a eficiência alimentar e de ruminação em caprinos Moxotó e Canindé em confinamento.

\section{Agradecimentos}

À CAPES pela concessão da bolsa de estudo. À Cicília Maria Silva de Souza, pela ajuda inestimável na condução e elaboração final deste trabalho. A Aldivan Rodrigues Alves, pela valiosa companhia e ajuda na condução das análises laboratoriais. A todos os alunos graduandos e pós-graduandos do CCA/UFPB, que passaram suas noites acordados fazendo observações do comportamento.

\section{Referências}

ALLEN, M.S. Physical constraints on voluntary intake of forages by ruminants. Journal of Animal Science, v.74, p.3063-3075, 1996.

ASSOCIATION OF OFFICIAL ANALYTICAL CHEMISTS - AOAC. Official methods of analysis of the association analytical chemists. 18.ed. Maryland: AOAC, 2005.

BAÊTA, F.C.; SOUZA, C.F. Ambiência em edificações rurais: conforto animal. Viçosa, MG: UFV, 1997. 246p.

BÜRGER, P.J.; PEREIRA, J.C.; QUEIROZ, A.C. et al Comportamento ingestivo em bezerros holandeses alimentados com dietas contendo diferentes níveis de concentrado. Revista Brasileira de Zootecnia, v.29, n.1, p.236-242, 2000.

CARDOSO, A.R.; CARVALHO, S.; GALVANI, D.B. et al. Comportamento ingestivo de cordeiros alimentados com dietas contendo diferentes níveis de fibra em detergente neutro. Ciência Rural, v.36, n.2, p.604-609, 2006.

CARVALHO, G.G.P.; PIRES, A.J.V.; SILVA, H.G.O. et al. Aspectos metodológicos do comportamento ingestivo de cabras lactantes alimentadas com farelo de cacau e torta de dendê. Revista Brasileira de Zootecnia, v.36, n.1, p.103-110, 2007

FERREIRA, A.V.; HOFFMAN, L.C.; SCHOEMAN, S.J. Water intake of Boer goats and mutton merinos receiving either a low of high energy feedlot diet. Small Ruminant Research, v.43, p.245-248, 2002.

FISCHER, V.; DESWYSEN, A.G.; DÉSPRÉS, L. et al. Padrões nectemerais do comportamento ingestivo de ovinos. Revista Brasileira de Zootecnia, v.27, n.2, p.362-369, 1998.

HADJIGEORGIOU, I.E.; GORDON, I.J.; MILNE, J.A. Intake, digestion and selection of roughage with different staple lengths by sheep and goats. Small Ruminant Research, v.47, p.117-132, 2003.

ÍTAVO, L.C.V.; VALADARES FILHO, S.C.; SILVA, F.F. et al. Níveis de concentrado e proteína bruta na dieta de bovinos Nelore nas fases de recria e terminação: Consumo e digestibilidade. Revista Brasileira de Zootecnia, v.31, n.2, p.1033-1041, 2002.

JOHNSON, T.R.; COMBS, D.K. Effects of prepartum diet, inert rumen bulk, and dietary polythylene glicol on dry matter intake of lactating dairy cows. Journal Dairy Science, v.74, n.3, p.933-944 1991.

LisBOA, A.C.C.; FURTADO, D.A.; MEDEIROS, A.N. et. al. Quantitative characteristics of the carcasses of Moxotó and Canindé goats fed diets with two different energy levels. Revista Brasileira de Zootecnia, v.39, n.7, p.1565-1570, 2010.

MENDONÇA, S.S.; CAMPOS, J.M.S.; VALADARES FILHO, S.C. et al. Comportamento ingestivo de vacas leiteiras alimentadas com dietas à base de cana-de-açúcar ou silagem de milho. Revista Brasileira de Zootecnia, v.33, n.3, p.723-728, 2004.

MERTENS, D.R. FDN fisicamente efetivo e seu uso na formulação de ração para vacas leiteiras In: SIMPÓSIO INTERNACIONAL DE BOVINOCULTURA DE LEITE: Novos conceitos em Nutrição, 2., 2001, Lavras. Anais... Lavras: Universidade Federal de Lavras, 2001. p.38. 
MERTENS, D.R. Regulation of forage intake. In: FORAGE QUALITY, EVALUATION, AND UTILIZATION, 1994, Wisconsin. Proceedings... Wisconsin, 1994. p.450-493.

MORAND-FEHR, P.; DOREAU, M. Ingestion et digestion chez les ruminants soumis à um stress de chaleur. INRA Production Animal, v.14, p.15-27, 2001.

NATIONAL.RESEARCH COUNCIL - NRC. Nutrient requirement of domestics animals: nutrient requirement of goats. Washington, D.C., 1981. 91p.

PAULINO, M.F.; MORAES, E.H.B.K.; ZERVOUDAKIS, J.T. et al. Fontes de energia em suplementos múltiplos de auto-regulação de consumo na recria de novilhos mestiços em pastagens de Brachiaria decumbens durante o período das águas. Revista Brasileira de Zootecnia, v.34, n.3, p.957-962, 2005.

PEREYRA, H.; LEIRAS, M.A. Comportamento Bovino de Alimentación, Rumia y Bebida. Fleckvieh-Simental, v.9, n.51, p.24-27, 1991.

POLLI, V.A.; RESTLE, J.; SENNA, D.B. et al. Aspectos relativos à ruminação de bovinos e bubalinos em regime de confinamento. Revista Brasileira de Zootecnia, v.25, p.987-993, 1996.

RIBEIRO, V.L.; BATISTA, A.M.V.; CARVALHO, F.F.R. et al. Avaliação do hábito seletivo de caprinos Moxotó e Canindé em confinamento através da granulometria do alimento. In: CONGRESSO NORDESTINO DE PRODUÇÃO ANIMAL, 4., 2006, Petrolina. Anais... Petrolina: Sociedade Nordestina de Produção Animal, [2006a]. (CD ROM).

RIBEIRO, V.L.; BATISTA, A.M.V.; CARVALHO, F.F.R. et al. Comportamento ingestivo de caprinos Moxotó e Canindé submetidos à alimentação à vontade e restrita Acta Scientarium Animal Sciences, v.28, n.3, p.331-337, 2006b.

SILANIKOVE, N. Effects of water scarcity and hot environment on appetite and digestion in ruminants: a review. Livestock Production Science, v.30, p.175-194, 1992.

SILVA, R.R.; SILVA, F.F.; CARVALHO, G.G.P. et al. Comportamento ingestivo de novilhas mestiças de Holandês x Zebu confinadas. Archivos de Zootecnia, v.54, p.75-85, 2005.

SILVA, J.F.C. Mecanismos reguladores de consumo. In: BERCHIELLI, T.T.; PIRES, A.V.; OLIVEIRA, S.G. (Eds.) Nutrição de ruminantes. Jaboticabal: Funepe, 2006. p. 57-77.

SNIFFEN, C.J.; O'CONNOR, J.D.; VAN SOEST, P.J. et al. A net carbohydrate and protein system for evaluating cattle diets: II. Carbohydrate and protein availability. Journal of Animal Science, v.70, n.3, p.3562-3577, 1992.

TAVARES, A.M.A.; VÉRAS, A.S.C.; BATISTA, A.M.V. et al. Níveis crescentes de feno em dietas à base de palma forrageira para caprinos em confinamento: Comportamento ingestivo. Acta Scientarium Animal Sciences, v.27, n.4, p.497-504, 2005.

TORREÃO, J.N.C. Níveis de energia em ovelhas Morada Nova no terço final da gestação e no pós-parto. 2007. 160f. Tese (Doutorado em Zootecnia) - Centro de Ciências Agrárias/ Universidade Federal da Paraíba, Areia.

VAN SOEST, P.J. Nutritiond ecology of the ruminant. 2.ed. Ithaca Cornell University Press, 1994, 476p.

WEISS, W.P. Energy prediction equations for ruminant feeds. In: CORNELL NUTRITION CONFERENCE FOR FEED MANUfACTURERS, 61., 1999, Ithaca. Proceedings, Ithaca: Cornell University, 1999. p.176-185. 